\title{
Significance of Alloying Element Levels in Realizing the Specified Tensile Properties in 18 wt\% Nickel Maraging Steel
}

\author{
Muktinutalapati Nageswara Rao ${ }^{*}$, Krishnan Sivasubramanian ${ }^{2}$ \\ ${ }^{1}$ Andhra University, Visakhapatnam, Indian Institute of Technology Bombay, University of Pennsylvania, Philadelphia, School of \\ Mechanical \& Building Sciences VIT University, Tamil Nadu, India; ${ }^{2}$ PSG College of Technology, Coimbatore, Mishra Dhatu Ni- \\ gam Limited, PO Kanchanbagh, Hyderabad, India. \\ Email: ${ }^{*}$ m.nageswararao@vit.ac.in
}

Received January $14^{\text {th }}, 2011$; revised May $19^{\text {th }}, 2011$; accepted May $26^{\text {th }}, 2011$.

\begin{abstract}
Among the various grades of commercially available $18 \mathrm{wt} \%$ nickel maraging steels, the one with nominal $0.2 \%$ proof strength in the range $1700-1750 \mathrm{MPa}$ is the most commonly used and is distinguished by an excellent combination of high strength and high fracture toughness. The main alloying elements are nickel, cobalt, molybdenum and titanium. The first three of these are present at relatively high concentrations in the chemical composition. The high cost of these metals leads to a high cost of production and this becomes a deterrent to extensive use of the steel. In the present study, an attempt was made to produce the steel by pegging the levels of these alloying elements in the lower half of the specified range. The objective was to save on the raw material cost, while still conforming to the specification. The steel so produced could not, however, attain the specified tensile properties after final heat treatment. The observed behavior is explained based on the role played by the different alloying elements in driving the precipitation hardening reaction.
\end{abstract}

Keywords: 18\% Ni Maraging Steel, Chemical Composition, Alloying Elements, Age Hardening, Tensile Properties

\section{Introduction}

18 wt\% Ni maraging steels based on iron-nickel martensite constitute a very important family of high strength steels. They distinguish themselves by demonstrating an unparalleled combination of high strength and high fracture toughness in heat treated condition and excellent hot and cold workability and weldability. Because of their high strength to weight ratio, they find extensive application in aerospace sector. Different grades of maraging steel are commercially available, covering the strength range of 1400 - $2400 \mathrm{MPa}$. With increasing strength level, the tensile ductility and fracture toughness decrease. Accordingly the lower strength variants are used where high ductility and fracture toughness are important for design. The higher strength variants are used where high strength is of paramount importance for design and one can manage with moderate levels of fracture toughness. Titanium is used as the primary strengthening element in these steels; precipitation of titanium bearing intermetallic particles in martensitic matrix in a uniform and finely dispersed manner during aging leads to development of very high strength levels. Aging has to be optimally carried out to realize the maximum strengthening effect. The 1988 symposium [1] deliberated on important developments and applications of maraging steels and more recently the metallurgy of $18 \% \mathrm{Ni}$ maraging steels has been reviewed by Rao [2].

An important factor that has come in the way of extensive use of $18 \% \mathrm{Ni}$ maraging steels is their high cost. Cobalt is an expensive alloying element and is present in the range of 8 to $12 \mathrm{wt} \%$ in these steels, contributing importantly to the cost. Accordingly efforts have been made to develop cobalt-free maraging steels with a comparable strength-fracture toughness combination. Cobalt-free maraging steel grades with strength levels covering the range 1400 - $2000 \mathrm{MPa}$ are now commercially available.

In addition to cobalt, the composition of $18 \% \mathrm{Ni}$ maraging steel prominently includes nickel and molybdenum; these elements are also costly and present in substantial quantity in the steel. Thus they contribute significantly to the production cost of the steel. 
With the levels of alloying elements in the middle / upper half of the specified range, material could be produced meeting the specified properties. An effort was made to contain the production cost of bar material by processing a batch of steel with the levels of the costly alloying elements - Co, Mo and $\mathrm{Ni}$ - in the lower half of the range allowed by the specification for chemical composition. The steel so produced has been evaluated and found to be not meeting the specification for tensile strength and yield strength. The paper gives the details of processing and evaluation of this batch and provides an explanation for the failure encountered in meeting the specified tensile properties.

\section{Material}

There was a requirement for $33 \mathrm{~mm}$ diameter bars of $18 \%$ $\mathrm{Ni}$ maraging steel grade conforming to Aerospace Materials Specification (AMS) 6512. The chemical composition of the steel as per this specification is given in Table 1. The tensile properties specified in AMS 6512 for the bar material are given Table 2 . The maraging steel was produced by double vacuum melting - vacuum induction melting (VIM) followed by vacuum arc remelting (VAR). Scrap of 18 wt\% Ni maraging steel was consolidated by melting in electric arc furnace. The liquid metal, at the end of arc furnace melting, was cast into a cylindrical electrode. The electrode material was subjected to electroslag remelting (ESR). The ESR processed material was then used as charge for vacuum induction melting. Small amounts of pure iron, molybdenum pellets, nickel shots and electrolytic cobalt were added to adjust the composition during vacuum induction melting. Standard practices for melting, refining and casting were followed for VIM processing. In order to explore the possibility for cutting down the raw

Table 1. Chemical composition of maraging steel, as specified in AMS 6512.

\begin{tabular}{cc}
\hline Element & wt\% \\
\hline Nickel & $17-19$ \\
Cobalt & $7.0-8.5$ \\
Molybdenum & $4.6-5.2$ \\
Titanium & $0.3-0.5$ \\
Aluminum & $0.05-0.15$ \\
Carbon & $<0.03$ \\
Iron & Balance \\
\hline
\end{tabular}

Table 2. Mechanical properties of the bar material as specified in AMS 6512.

\begin{tabular}{ll}
\hline Property & Specification \\
\hline Ultimate tensile strength (MPa) & $1758 \mathrm{~min}$ \\
$0.2 \%$ Proof strength $(\mathrm{MPa})$ & $1724 \mathrm{~min}$ \\
$\%$ Elongation & $6 \mathrm{~min}$ \\
$\%$ Reduction in area & $40 \mathrm{~min}$ \\
\hline
\end{tabular}

material cost and in turn the production cost, while still conforming to the specification, one batch of the steel was processed through VIM with levels of the costly elements - Co, Mo and $\mathrm{Ni}$ - aimed in the lower half of the specified range for the respective elements. Detailed chemical analysis of the batch at this stage was carried out and the results are given in Table 3. The molten metal was tapped in to a $480 \mathrm{~mm}$ diameter mould. The 480 $\mathrm{mm} \phi$ electrode was conditioned and remelting was done in a VAR furnace to produce a $550 \mathrm{~mm} \phi$ ingot.

The VAR ingot was subjected to hot working, comprising of hot forging in a press, hot forging in hammer and finally hot rolling to realize the material in the form $33 \mathrm{~mm} \phi$ bars. Conditioning of the material during hot working was carried out as necessary. Detailed chemical analysis of the material was again carried out at the bar stage; the results were found to match with those obtained at VIM stage, except for a small drop in titanium level from 0.43 to 0.41 and aluminum level from 0.095 to 0.090 .

\section{Results}

The $33 \mathrm{~mm} \phi$ hot rolled bar material was taken up for heat treatment. The treatment comprised of two stages (1) Soaking at $950^{\circ} \mathrm{C}$ followed by forced air cooling and (2) Soaking at $820^{\circ} \mathrm{C}$ followed by air cooling. Tensile properties were evaluated after carrying out aging of the material. The temperature used for aging was $485^{\circ} \mathrm{C}$. The aging time normally adopted is 3 hours, but the specification allows aging time up to 6 hours. Aging for $3 \frac{1}{2}$ hours resulted in the UTS and $0.2 \%$ PS values not meeting the specification. Aging was then continued and tensile properties evaluated after cumulative aging times of 6 , 12 and 15 hours. There was steady improvement in both $0.2 \%$ PS and UTS values with increasing aging time, but even after 15 hours the proof strength values were not all above the specified minimum. Table 4 gives the details. On the other hand, heats made with standard practice, where the levels of individual alloying elements are maintained in the middle/upper half of the specified range, showed acceptable $0.2 \%$ PS and UTS values after

Table 3. Chemical composition of the batch produced with low levels of alloying elements, after VIM (wt\%).

\begin{tabular}{cc}
\hline Element & $\mathrm{Wt} \%$ \\
\hline Carbon & 0.009 \\
Sulfur & 0.0016 \\
Phosphorous & 0.006 \\
Nickel & 17.6 \\
Cobalt & 7.6 \\
Molybdenum & 4.7 \\
Titanium & 0.43 \\
Aluminum & 0.095 \\
Iron & Balance \\
\hline
\end{tabular}


Table 4. Mechanical properties obtained on $33 \mathrm{~mm} \phi$ hot rolled and heat treated bars from the batch under study, as a function of aging time. Solution treatment: $950^{\circ} \mathrm{C} 1$ hour followed by forced air cooling to room temperature; $820^{\circ} \mathrm{C} 1$ hour followed by air cooling Aging temperature: $485^{\circ} \mathrm{C}$ Aging is followed by air cooling.

\begin{tabular}{ccccc}
\hline Aging time (Hours) & $\begin{array}{c}0.2 \% \text { Proof strength } \\
(\mathrm{MPa})\end{array}$ & $\begin{array}{c}\text { Ultimate tensile strength } \\
(\mathrm{MPa})\end{array}$ & \% Elongation & \% Reduction in area. \\
\hline 3.5 & $1606-1640$ & $1670-1690$ & $12-13$ & 63 \\
6 & $1668-1679$ & $1736-1740$ & 13 & $57-61$ \\
12 & $1709-1730$ & $1762-1772$ & $11-14$ & $57-62$ \\
15 & $1718-1742$ & $1775-1785$ & $12-13$ & $58-62$ \\
\hline
\end{tabular}

3.5 hours of aging and the values remained essentially constant until cumulative aging time of 15 hours, for which data are available. Figure 1 shows variation of $0.2 \%$ proof strength and ultimate tensile strength as a function of aging time on a comparative basis for the batch under study and heats made as per standard practice. It is to be emphasized that aging of the samples from the batch under study has been done under conditions identical to aging of samples from heats made as per standard practice. The difference in the aging behavior, as shown in Figure 1, is hence indeed due to different response of the material from the batch under study to aging treatment.

Microstructural examination was carried out on samples drawn from the bar material after aging. The microstructure comprised of aged martensite. The prior austenitic grain size was fine, 7 to 8 on ASTM scale. Similar grain size values were obtained on bars from heats processed as per standard practice. Inclusion rating was carried out in the unetched condition as per ASTM E45. The rating of thin oxides was 0.5 ; the ratings for the sulfide, silicate and alumina type inclusions were zero. Carbide / carbonitride particles were seen, but their content was well within acceptable limits. Similar inclusion ratings were obtained in heats made with recycling scrap forming only a minor part of the total charge weight.

\section{Discussion}

Even though it is a heat made of $100 \%$ scrap of maraging steel, this is not believed to be responsible for the observed failure in realizing the specified strength level. The higher percentage of scrap, if it made a difference, is expected to get reflected in the inclusion rating. However, the inclusion rating in the batch under study was found to be similar to the rating observed in heats made with recycling scrap forming only a minor part of the total charge weight. Further, experience has shown that inclusion rating affects more the percent elongation and percent reduction in area values and for the batch in question, measured values for these two attributes were comfortably above the respective minimum specified values.

It is to be noted that the $0.2 \%$ proof strength and ultimate tensile strength values as per AMS 6512 are considerably higher than those specified in other specifications covering this material. Table 5 brings out this comparison. What this means is that the bar material under discussion had to be produced to a relatively high strength level.

The observed grain size in fully heat treated condition was very fine -7 to 8 on ASTM scale. Figure 2 shows the typical microstructure in fully heat treated condition. Similar grain size was observed in heats made as per standard practice. Hence the Hall-Petch strengthening in the batch under study is the same as that in the heats made as per standard practice. In spite of this the measured strength in the batch under study is falling short of specification.

Nickel level in the batch studied (17.6 wt\%) lies in the lower half $(17-18 \%)$ of the AMS 6512 specification. The $\mathrm{M}_{\mathrm{s}}$ and $\mathrm{M}_{\mathrm{f}}$ temperatures are influenced by the Ni level. Nickel level also influences the aging temperature / time at which austenite reversion sets in. The composition of the maraging steel is designed such that (i) martensitic transformation is complete well before the steel cools down to room temperature and (ii) austenite reversion does not occur with the time / temperature combinations normally employed for aging. The microstructure of the batch under study in the solution treated condition was found to contain $<2 \%$ retained austenite. The microstructure even after aging for 15 hours at $485^{\circ} \mathrm{C}$ had a volume fraction of austenite $<2 \%$. The design requirements are thus fully met even at this slightly lower level of Ni. The lower Ni level could possibly mean lower activity of $\mathrm{Ni}$ in Fe-Ni martensite, and a reduced driving force for $\mathrm{Ni}_{3}(\mathrm{Ti}, \mathrm{Mo})$ precipitation to occur, with the consequence of a lowered strength level obtained after a given aging temperature / time combination.

The range for molybdenum in the steel, as per AMS 6512 is 4.6 to 5.2. The range for Mo for equivalent grade supplied by Carpenter Steel (Carpenter NiMark Alloy 250) [3], for example, is 4.7 to $5.0 \mathrm{wt} \%$. The level of Mo in the batch under study corresponds to lower limit of the range. This again means a reduced driving force for Mo to precipitate out as $\mathrm{Ni}_{3}(\mathrm{Ti}, \mathrm{Mo})$; the consequence again would be attainment of a reduced strength level after aging for a given time / temperature combination.

The cobalt level in the steel under investigation (7.6 wt\%) is in the lower half of the range specified by AMS 6512. This level appears to be somewhat lower than required. There is evidence that Co level in this grade is peg- 
Table 5. Minimum $0.2 \%$ PS and UTS values specified for the maraging steel grade under discussion as per different standards.

\begin{tabular}{lll}
\hline Standard & $0.2 \%$ PS (MPa) & UTS (MPa) \\
\hline DIN EN3529 (1999) for Aerospace forgings & 1620 & 1720 \\
MIL-S-46850D (1991) for bars, forgings, sheets, strips, plates & - & 1655 \\
ASTM A538 (1982) for pressure vessel plates (withdrawn in 1987) & 1580 & 1650 \\
AMS 6512E (2005) for bars, forgings, rings & 1724 & 1758 \\
\hline
\end{tabular}

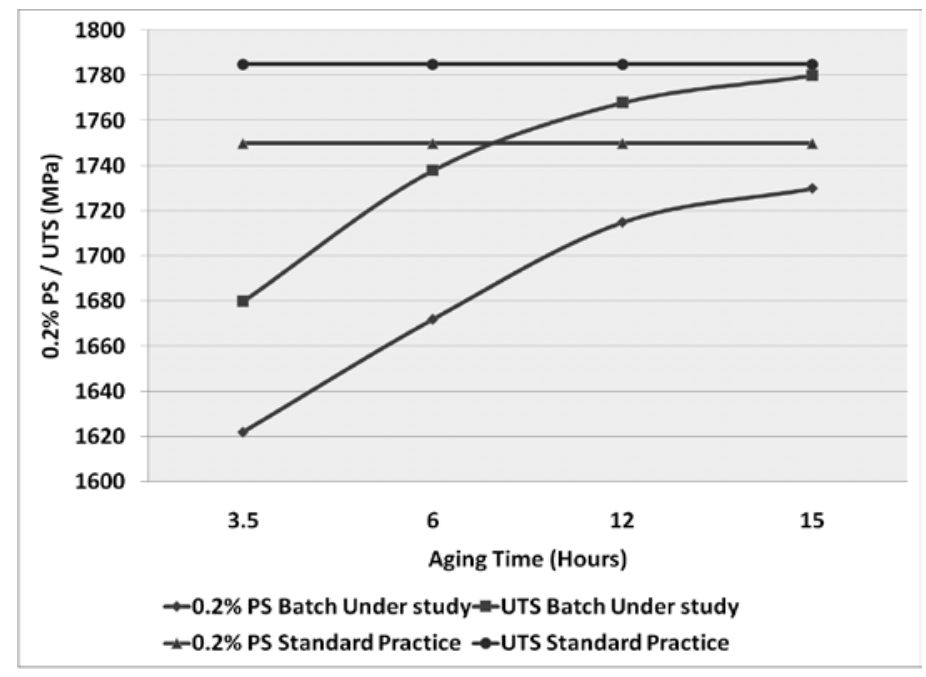

Figure 1. Variation of $0.2 \%$ PS and UTS as a function of aging time for the batch under study (with low levels of alloying elements) and for the heats made with standard practice.

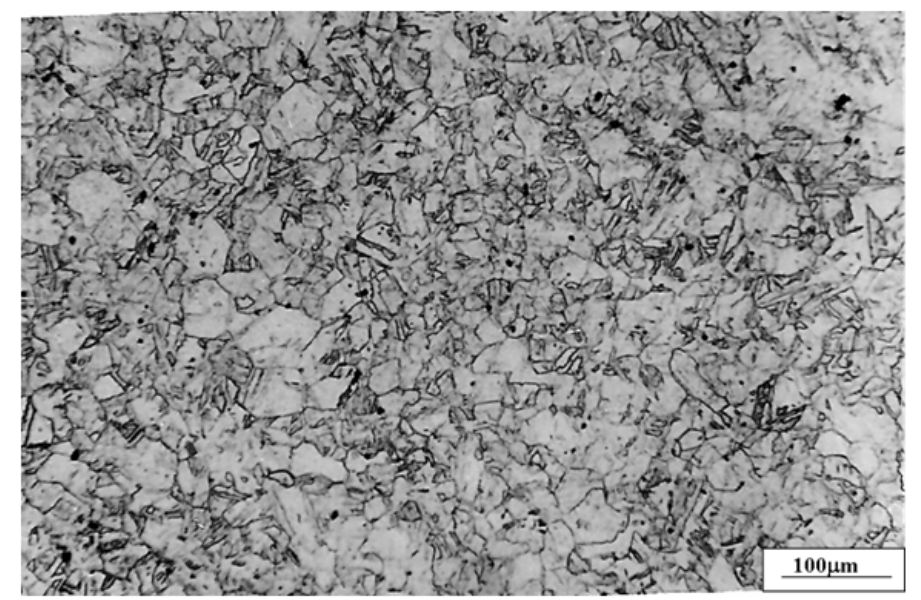

Figure 2. Typical microstructure of the maraging steel bars in fully heat treated condition.

ged at 7.8 to $8.0 \mathrm{wt} \%$ [4-6]. The role of Co on the lowering of solid solubility of Mo in Fe-Ni martensitic matrix has been well established [1,7]. With Co present at a lower level, there will be, to that extent, a reduced effect of lowering of the solid solubility of Mo in martensite and correspondingly a reduced precipitation of Mo bearing age-hardening precipitate $\mathrm{Ni}_{3}$ (Ti,Mo) after aging for a given time / temperature combination.

Titanium level in the steel under study is $0.41 \mathrm{wt} \%$. There is evidence that $\mathrm{Ti}$ in this grade is pegged at a level of $0.45 \mathrm{wt} \%[4,5]$. Values as high as $0.55 \mathrm{wt} \% \mathrm{Ti}$ have been adopted by Boehler Edelstahl for their equivalent grade [6]. Titanium contributes importantly to strengthening by precipitating in the form of titanium bearing 
particles $\mathrm{Ni}_{3}(\mathrm{Ti}, \mathrm{Mo})$, leaving undetectable amount $(<0.1$ wt\%) of Ti in the matrix [7]. It is hence concluded that a somewhat higher level of $\mathrm{Ti}$ would have facilitated reaching the specified strength level. The level of aluminum $(0.09 \%)$ is slightly below the middle of the specified range $(0.1 \%)$. This is expected to have very small effect on the strength, considering that strengthening effect of $\mathrm{Al}$ is $5.6-6.3 \mathrm{~kg} / \mathrm{sq} \cdot \mathrm{mm}$ (55 - $62 \mathrm{MPa}$ ) per $0.1 \mathrm{wt} \%$ [8].

If the microstructure after aging contains considerable amount of austenite, this could lead to a relatively low level of yield strength, as austenite is a soft phase compared to aged martensite. In the present case, however, austenite is present in the aged microstructures at a level of $<2 \%$. Hence this is not a causative factor for the steel not responding satisfactorily to the aging treatment.

Aging has been continued till 15 hours and tensile properties evaluated. There is a steady increase in the strength with aging time; however, even after aging for 15 hours, not all values of $0.2 \%$ proof strength met the specification. Further it is necessary in industrial practice to have a steel composition which will respond to the aging treatment and lead to attainment of specified mechanical properties in a relatively short time, say 3 to 6 hours, from the productivity point of view.

It thus becomes clear that adhering to AMS 6512 with respect to chemical composition, by itself, is not sufficient to meet the specification with respect to mechanical properties. As mentioned in the results section, heats made with the standard practice, where the levels of individual alloying elements are maintained in the middle / upper half of the specified range showed acceptable $0.2 \%$ PS and UTS values after 3.5 hours of aging. The solution to consistently producing the material with total conformity to AMS 6512 hence lies in producing the melts with levels of $\mathrm{Ni}, \mathrm{Co}, \mathrm{Mo}$ and $\mathrm{Ti}$ in the middle or even in the upper half of the range specified in the AMS.

\section{Conclusions}

1) Maintaining the levels of alloying elements within the range specified in AMS 6512 for $18 \mathrm{wt} \%$ nickel maraging steel is not sufficient to realize the strength levels specified in the same Standard.

2) It is believed that the relatively low levels of Ni, Mo and $\mathrm{Ti}$ within the specified range, tried out for reducing the cost of production, lead to a relatively low volume fraction of $\mathrm{Ni}_{3}(\mathrm{Ti}, \mathrm{Mo})$; this causes lower than the required precipitation strengthening effect.

3) The relatively low level of Co tried out appears to be resulting in a less decrease in solid solubility of Mo in the martensitic matrix, thereby leading to reduced extent of precipitation of Mo and consequently reduced amount of precipitation strengthening.

4) The standard practice of melting, with particular emphasis to pegging the levels of $\mathrm{Ni}, \mathrm{Co}$, Mo and $\mathrm{Ti}$ in the middle or upper half of the range specified in AMS 6512, has to be adopted if material meeting this specification in all respects is to be produced.

\section{Acknowledgements}

M Nageswara Rao is grateful to the Management of VIT University for their kind consent to publish this paper. $\mathrm{K}$ Sivasubramanian is indebted to the management of MIDHANI for encouragement and permission to publish the results.

\section{REFERENCES}

[1] R. K. Wilson, "Maraging Steels: Recent Developments and Applications,” The Minerals, Metals \& Materials Society, Warrendale, Pennsylvania, 1988.

[2] M. N. Rao, "Progress in Understanding the Metallurgy of 18\% Nickel Maraging Steels," International Journal of Materials Research, Vol. 97, No. 11, November 2006, pp. 1594-1607.

[3] “NiMark Alloy 250,” Internet Available: http://www.cartech.com/ssalloysprod.aspx?id

[4] P. P. Sinha, D. Sivakumar, T. Tharian, K. V. Nagarajan and D. S. Sarma, "Thermal Embrittlement in 18Ni Cobalt Free and 18Ni-8Co-5Mo Maraging Steels,” Materials Science and Technology, Vol. 12, November 1996, pp. 945-954.

[5] P. P. Sinha, K. Sreekumar, N. S. Babu, B. Pant, A. Natarajan and K. V. Nagarajan, "Development of Heat Treatment Parameters to Improve Fracture Toughness and Grain Size of an Embrittled Maraging Steel,” Journal of Heat Treating, Vol. 9, No. 2, 1992, pp. 125-131. doi:10.1007/BF02833148

[6] P. Wuerzinger, R. Rabitsch R and W. Meyer, "Production of Maraging Steel Grades and the Influence of Specified and Nonspecified Elements for Special Applications," Journal of Materials Science, Vol. 39, No. 24, 2004, pp. 7295-7302. doi:10.1023/B:JMSC.0000048744.03279.ec

[7] W. Sha, A. Cerezo and G. D. W. Smith, "Phase Chemistry and Precipitation Reactions in Maraging Steels: Part IV, Discussion and Conclusions,” Metallurgical Transactions A, Vol. 24A, No. 6, June 1993, pp. 1251-1256. doi:10.1007/BF02668193

[8] A. G. Haynes, "The Making, Shaping and Heat Treating of $18 \%$ Ni Maraging Steels," Proceedings of ASPA Seminar, Madras, 1978, p. 38 